Abstracta Iranica Abstracta Iranica

Revue bibliographique pour le domaine irano-aryen

Volume 27 | 2006

Comptes rendus des publications de 2004

\title{
The Buddhist Architecture of Gandhāra. Leiden, Brill, 2004, 335 p. (Handbuch der Orientalistik II-17)
}

Étienne de La Vaissière

\section{Q OpenEdition}

1 Journals

Édition électronique

URL : http://journals.openedition.org/abstractairanica/5633

DOI : $10.4000 /$ abstractairanica.5633

ISSN : 1961-960X

\section{Éditeur :}

CNRS (UMR 7528 Mondes iraniens et indiens), Éditions de l'IFRI

\section{Édition imprimée}

Date de publication : 15 mai 2006

ISSN : 0240-8910

\section{Référence électronique}

Étienne de La Vaissière, « The Buddhist Architecture of Gandhāra. Leiden, Brill, 2004, 335 p. (Handbuch der Orientalistik II-17) », Abstracta Iranica [En ligne], Volume 27 | 2006, document 41, mis en ligne le 02 janvier 2007, consulté le 25 septembre 2020. URL : http://journals.openedition.org/abstractairanica/ 5633 ; DOI : https://doi.org/10.4000/abstractairanica.5633

Ce document a été généré automatiquement le 25 septembre 2020.

Tous droits réservés 


\title{
The Buddhist Architecture of Gandhāra. Leiden, Brill, 2004, 335 p. (Handbuch der Orientalistik II-17)
}

\author{
Étienne de La Vaissière
}

Cette analyse technique de l'architecture bouddhiste du Gandhāra a pour intérêt principal de proposer une classification de l'énorme documentation conservée autour de ce thème, à la fois grâce aux restes architecturaux eux-mêmes, aux sculptures mais aussi aux photographies réalisées lors des fouilles. L'A. traite particulièrement de ce qu'il appelle le Gandhāra ancien, ou Gandhāra à proprement parler, le bassin agricole de Peshawar et qu'il faut distinguer du Grand Gandhāra, la sphère de diffusion de la culture gandharienne, incluant souvent le Swāt et Taxila. Après avoir présenté les sites de l'ancien Gandhāra, ceux de Taxila et ceux du Swāt, puis les différentes formes architecturales, l'A. les classe en quatre phases (I : de la fin du $3^{\mathrm{e}} \mathrm{s}$. av. n. è. au milieu du $1^{\text {er }} \mathrm{s}$. de n.è., II : du milieu du $1^{\text {er }}$ s. de n.è au début du $3^{\mathrm{e}} \mathrm{s}$.; III : du début du $3^{\mathrm{e}} \mathrm{s}$. à la fin $\mathrm{du} 5^{\mathrm{e}} \mathrm{s}$. et enfin IV : jusqu'à la fin du $8^{\mathrm{e}} \mathrm{s}$. de $n$. è.). Il procède ensuite phase après phase et dans chacune d'elles site par site. Un chapitre final récapitule en une synthèse chronologique l'ensemble des découvertes. Abondantes illustrations (photos, plans, dessins).

\section{INDEX}

Thèmes : 3.1. Est de l'Iran 
AUTEURS

ÉTIENNE DE LA VAISSIÈRE

ENS - EPHE - Paris 